\title{
COPPER IN THE TREATMENT OF NUTRITIONAL AN/EMIA IN INFANCY
}

\author{
BY \\ HELEN M. M. MACKAY, M.D., M.R.C.P.* \\ (From the Queen's Hospital for Children, London.)
}

Ample evidence now exists to show that the nutritional anæmia, or milk anæmia, of babies bears a very close resemblance to the milk anæmia of rats, but whereas young rats in whom anæmia is induced by prolonged milk feeding suffer from a deficiency of copper as well as of iron, and require both copper and iron for their cure ${ }^{4}$, it is not yet proven that copper deficiency plays any part in the ordinary case of nutritional anæmia in the human infant. This study was undertaken in the hope of providing further evidence on this question.

The mode of action of copper. - The actual mode of action of copper is unknown, but recent experimental work has thrown some light on the question. Elvehjem, Steenbock and Hart ${ }^{1}$ state that it is not a constituent of the hæmoglobin molecule. In the absence of copper, iron supplied to young rats by mouth is absorbed from the intestine, and is stored chiefly in the liver, as Josephs has shown ${ }^{6}$, but is not used for building hæmoglobin. If copper is given it renders this iron utilizable for hæmoglobin formation: ' copper does not affect the assimilation of iron, but does function in the conversion of inorganic iron into hæmoglobin '.

Görter, Grendel and Weyers ${ }^{3}$ have shown that in a small series of children suffering apparently from nutritional anæmia, the copper content of the blood was more than twice as high as in the new-born and markedly higher than in control convalescent children, a fact which suggests (a) that in these cases of anæmia there was no shortage of copper, and (b) that the body's need for hæmoglobin calls out copper into the circulation.

The response to treatment with an iron salt.-The author ${ }^{8}$ has already shown that iron and ammonium citrate will cure the vast majority of cases of nutritional anæmia in babies in London provided there is no serious infection present ${ }^{9}$. In some infants the response is very slow, but sometimes in such instances there will be found slight pyrexia, presumably from an undiscovered infection which is retarding cure. The iron and ammonium citrate successfully used in this investigation contained, however, a trace of copper, $1.7 \mathrm{mgrm}$. per $100 \mathrm{grm} .{ }^{10}$, and thus left open the possibility that the trace of copper was a material factor in the results obtained. This hypothesis

* Working as a member of the scientific staff of the Medical Research Council, 
nevertheless seems improbable, as the copper added to the diet by the iron salt amounted to a very small percentage of the total copper intake. Even when the babies were entirely bottle fed, and so getting food especially low in copper, the increase in copper due to the iron salt wotild only amount to, say, 4 per cent. It is not easy to be convinced that a rise in copper intake from 1.26 mgrm. to $1.31 \mathrm{mgrm}$. weekly, which is the approximate figure for a baby in our series getting $1 \frac{1}{2}$ pints of milk daily, is likely to have been a material factor in the cure.

If the deficiency in babies suffering from nutritional anæmia is generally a combined deficiency of both iron and copper, one might anticipate a better response to treatment with an iron salt in those receiving more copper in their food than in those receiving much less. Babies on a mixed diet get much more copper than those on cow's milk alone, but iron and ammonium citrate appears to cure at about the same rate whether the baby is entirely bottle fed or is given mixed food ${ }^{5,11}$. This fact might be used as an argument against a deficiency of copper in these babies, but here we seem on uncertain ground. There is no doubt that iron deficiency is present, yet in a clear case of nutritional anæmia inorganic iron, in doses which are vast compared with the total iron of the body, produces a better response than does the organic iron present in an ordinary mixed diet containing eggs, meat, green vegetables, etc. ${ }^{12}$ Hence if inorganic iron in large doses is the best method yet known of making good an iron deficiency, it is possible that inorganic copper, also in relatively large doses, might be the best method of making good a copper deficiency. So that this argument against a copper deficiency, because a similar rate of response is obtained with iron whether the food copper is low or not, seems by itself inconclusive.

The influence of copper.-During the last few years a number of articles have been published on the treatment of anæmia in the human subject by the administration of copper. At least one of these was based on a series of one hundred children treated with iron and copper, but unfortunately few of the papers give sufficient data to allow the reader to reach any conclusions as to the value of copper therapy in the nutritional anæmia of babies.

On the other hand, Josephs has carried out at the Johns Hopkins Hospital some interesting and valuable work on anæmia in babies, and his cases have been accepted by many as proof that in nutritional anæmia of infancy copper and iron administered together produce a more rapid rise in hæmoglobin than iron alone ${ }^{5}$. However, the majority of the cases quoted in his paper were suffering from, or had begun to be convalescent from, some serious infection, such as pneumonia, empyema, tuberculosis or syphilis; and some at least were presumably receiving other forms of treatment in addition, which makes it difficult to draw any clear cut conclusions; for he himself, in another important paper ${ }^{7}$ demonstrates the blood destruction occurring during severe infections, and the variations that exist in the subsequent tendency to ' spontaneous cure.' The number of Josephs' published cases 
(including controls and cases treated with copper), which were uncomplicated by any serious infection was 6, starting treatment at hæmoglobin levels ranging between 30 and 50 per cent. Though these cases certainly suggest that the copper supplement (copper sulphate) may have accelerated cure of the anæmia when given in addition to iron (iron and ammonium citrate), yet the number of cases is too small to be conclusive (only 3 were given iron plus copper throughout the time of treatment) in view of the great individual variations in response to iron and ammonium citrate without added copper. Moreover, some of Josephs' cases were first given iron alone and later iron

GRAPH I.

Results of treatment (for Cases see p. 153).

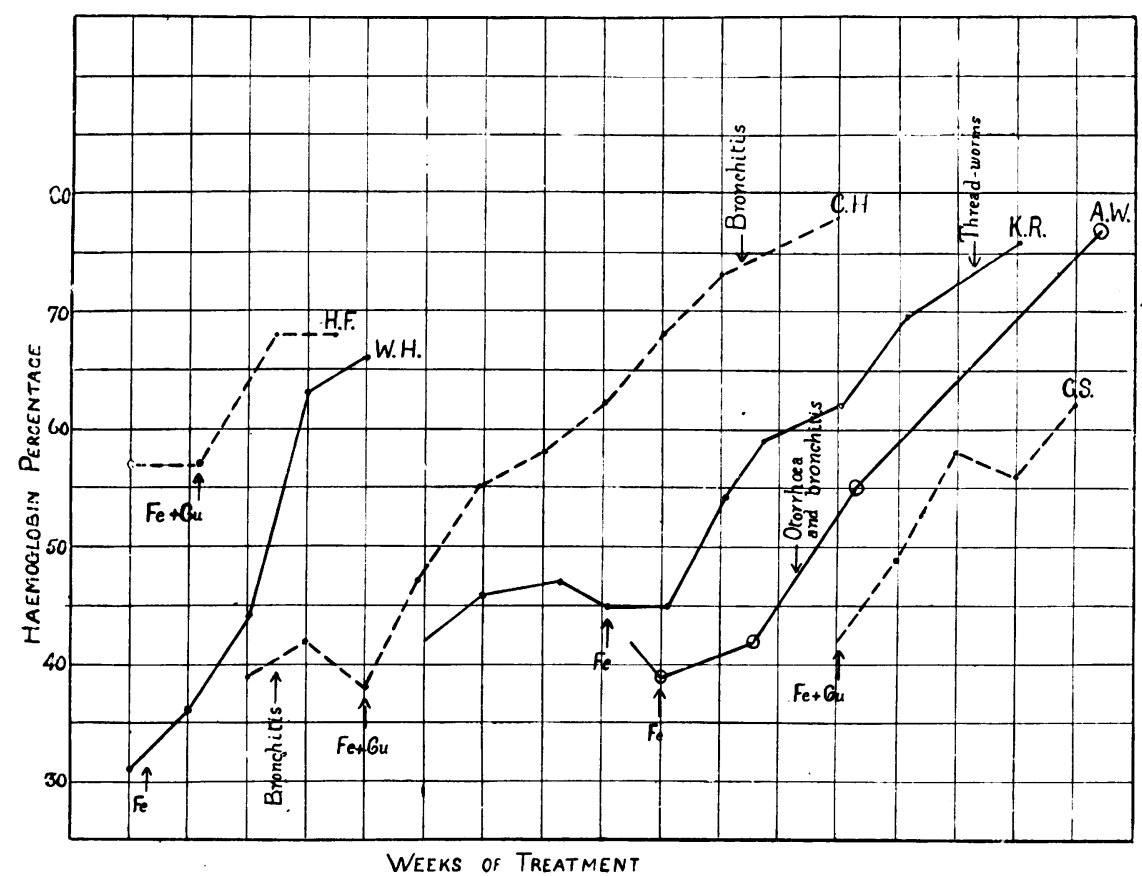

Iron and ammonium citrate plus copper sulphate Iron and ammonium citrate alone Saccharated ferrous carbonate

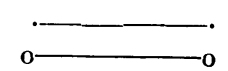

plus copper. In the experience of the present author not only do some babies respond with a more rapid rise than others to iron, even when the initial hæmoglobin levels correspond, but the individual baby often does not show an even rise (see Graphs I and II). The rise with iron treatment tends to be most rapid when the initial hæmoglobin level is low, and, as Joseph $\mathbf{s}^{5}$ and others have pointed out, in many cases the rise tends to be slower and more irregular as the hæmoglobin level approaches normal. On the other hand, occasionally a child may show little response to iron treatment for a month or even more, and subsequently his hæmoglobin may rise rapidly. Hence to 
compare a child's initial response to iron to its subsequent improvement on iron plus copper seems likely to lead to an erroneous conclusion. Since Josephs does not state that his iron salt was copper-free, the presumption is that it, like most other iron salts on the market, including that used by the present author, contained traces of copper.

\section{Present investigations.}

To demonstrate satisfactorily that iron and copper together produce a better response than iron alone in nutritional anæmia, it seems desirable to compare a series of similar babies treated throughout with both minerals

GRAPH II.

Results of treatment (for Cases see p. 153).

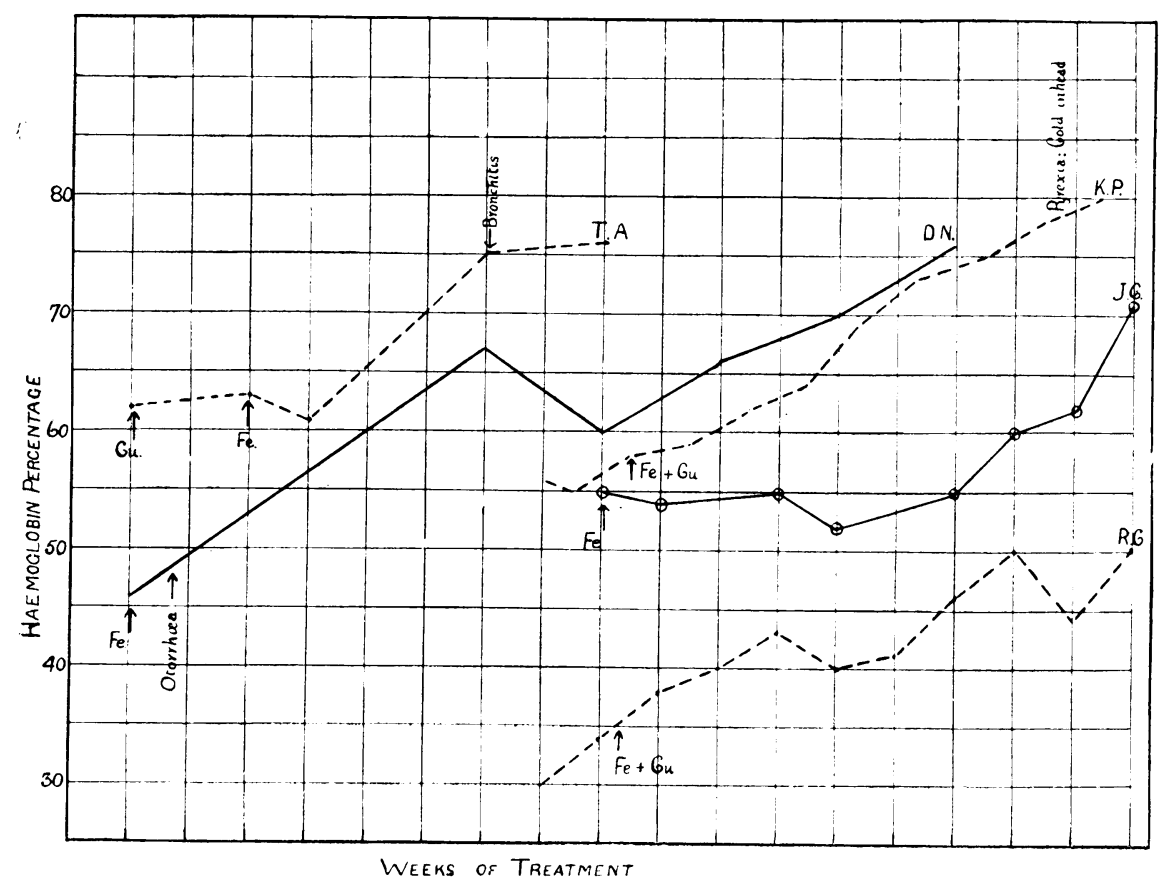

Iron and ammonium citrate plus copper sulphate

Iron and ammonium citrate alone

Saccharated ferrous carbonate

with a series treated with iron alone, climinating as far as possible any complicating factors, such as intercurrent illness, etc. This the author has attempted, but with only partial success. As everyone who has attempted such work is aware, there are various difficulties to be overcome, and the observations here described are not in themselves conclusive, though it is hoped that taken in conjunction with other work they may help to clarify the problem. 
There were certain advantages in using iron in the form of iron and ammonium citrate, because the use of this salt in most of her previous work on nutritional anæmia had rendered the author familiar with the type of response to be expected from it. Failing, however, to get iron and ammonium citrate free from traces of copper, the salt used was obtained from the same firm as before, the British Drug Houses. Both groups of children were given this iron salt, and the ' copper group' received in addition a supplement of copper sulphate. If the babies under observation suffered from copper deficiency then more rapid cure should be obtained by giving iron with an ample copper supplement, than by giving iron with only a trace of copper impurity which could scarcely make good an existing deficiency.

The second difficulty was to obtain sufficient numbers of uncomplicated cases and to ensure that they received regular treatment. In the author's iron work regular administration of the iron salt could be obtained in outpatients because the iron was incorporated in dried milk, whereas in this work, done on a small scale, the copper was given in the form of a mixture. Hence whenever possible it was desirable to treat the babies as in-patients. The great susceptability of anæmic infants to infections of all sorts renders their in-patient treatment difficult, and a number of cases had to be excluded because they suffered from infections, while others were discharged for their own safety, before any result was obtained, on account of ward infection.

Dosage of IRON AND AMMONIUM cITRATE.-The dosage of iron used in the cases illustrated in this paper varied between $4 \frac{1}{2}-9$ grn. of iron and ammonium citrate daily. In every case, however, the iron was begun gradually, so that the amount given in the first week amounted to considerably less than this quantity.

Dosage of copper sulphate.-Except for one of the cases (H.C., Graph II), the copper supplement was one-twentieth of a grain of copper sulphate $\left(\mathrm{CuSO}_{4}, \mathbf{5} \mathrm{H}_{2} \mathrm{O}\right)$ daily, divided into three doses. This also was begun gradually. This dose of copper sulphate is smaller, weight for weight, than the dose given by Hart and his colleagues at Wisconsin to their rats. These workers found 0.05 mgrm. of copper as copper sulphate, given on six days in the week, a satisfactory supplement for a young rat, and that $0.01 \mathrm{mgrm}$. of copper would produce cure, though more slowly. They calculated ${ }^{4}$ that $0.05 \mathrm{mgrm}$. of copper increased the copper intake say six-fold. If we assume that the young rat's weight is about $60 \mathrm{grm}$. then weight for weight the amount needed by a 14-lb. baby would be about one-fifteenth to one-third of a grain of copper sulphate daily. But when one remembers that the rate of increase in weight of young rats is so much more rapid than that of babies it seems probable that the copper needs of babies would be relatively less. The dose actually used by the author, as stated above, was onetwentieth of a grain of copper sulphate daily. The doses given by Josephs varied with the child's weight. For babies of $14 \mathrm{lb}$. his doses were about ten times as large as the author's, or about $\frac{1}{2}$ grain of copper sulphate daily ( $\frac{1}{4}$ to $\frac{1}{2}$ grain is given as the ' average' adult dose by Martindale $\&$ Westcott 
in the Extra Pharmacopœia). Josephs' dosage was, he says, well tolerated in babies, but the progressively larger amounts for older and heavier children sometimes caused diarrhœa and vomiting.

One case illustrated in Graph II (R.C.) received a much smaller dose of copper than the rest of the cases shown, namely a dose of $0.12 \mathrm{mgrm}$. copper sulphate (or about $\mathbf{0 . 0 3} \mathrm{mgrm}$. $\mathrm{Cu}$ ) daily, an amount which approximately trebled the copper addition to the diet provided by the traces of copper in the iron and ammonium citrate. This was given with the idea that if the traces of copper in the iron salt used were playing any part in the results obtained, then trebling this trace should intensify the effect.

Dosage of Saccharated Ferrous carbonate. As a matter of interest two cases given saccharated ferrous carbonate are also shown on the charts. The dosage of saccharated ferrous carbonate, $4 \frac{1}{2}-9$ grains daily, was, as regards iron content, similar to that of the iron and ammonium citrate given. Iron and ammonium citrate contains approximately 20 per cent. of iron, and the saccharated ferrous carbonate, say, 25 per cent.

Results. - The number of uncomplicated cases treated with the copper supplement in this series is much too small to warrant the calculation and comparison of the average rates of response to the two methods of treatment, though this would undoubtedly be the method of choice were the numbers large enough. However, since they are not, the individual responses to treatment with iron and copper combined are compared with typical responses to treatment with iron and ammonium citrate alone. Several of the babies suffered from minor infections (e.g., nasal discharge and bronchitis), but all children with severe infections have been excluded.

In Graph $I$ is shown the best response obtained with iron and ammonium citrate plus the copper supplement, a rise of 40 per cent. in 56 days (C.H.); and with it two examples (W.H. and K.R.), of good response with the iron and ammonium citrate alone, in one case a rise of 35 per cent. in 24 days (W.H.), and in the other a rise of 31 per cent. in 49 days (K.R.). For purposes of comparison one case (A.W.) on saccharated ferrous carbonate is included, with a rise of 38 per cent. in $\mathbf{5 3}$ days. It will be seen that all four cases show a response of the same order; the baby who has the lowest initial hæmoglobin showing the most rapid rise in hæmoglobin level. There is not one case among those given the copper supplement that cannot be matched, or even bettered, by cases treated with iron and ammonium citrate alone.

Graph II (R.C.) shows the poorest response obtained with iron and copper in an apparently uncomplicated nutritional anæmia. This was a very anæmic baby (30 per cent. hæmoglobin) with a slow and irregular rise of only 16 per cent. in $\mathbf{5 9}$ days, although there was no evidence of any microbic infection. This infant received the very small copper addition mentioned above, and the response was unusually poor for a child given iron and ammonium citrate.

The other curves on the two charts (Graph I, H.F. and C.S.; Graph II, T.A. and K.P.) show intermediate results. J.C. shown in Graph II, who was given saccharated ferrous carbonate, is included because of his very long 
' latent period.' No evidence of infection was present and he was known to have regular treatment. There was no rise in hæmoglobin for 6 weeks, and thereafter a fairly rapid rise: 16 per cent. in 21 days, without change of treatment. In such a case if copper had been added during this long ' latent period' one would have been inclined to attribute the subsequent rise to the new factor.

\section{Discussion and conclusions.}

The comparison of cases treated with and without the copper supplement does not suggest that copper was of any benefit in this type of anæmia : in fact, the types of response obtained with copper were very like those customarily seen with iron and ammonium citrate alone. From which it seems fair to conclude that the deficiency affecting these babies was a deficiency of iron and not of iron plus copper. The successful results of treatment with a copper-free salt published in the present number of this journal by Professor Parsons and his colleagues lead to the same conclusion and are of great importance.

The facts set forth when taken together indicate, in the author's opinion, that copper deficiency does not play any important part in the common nutritional anæmia of babies in this country. Such negative results, however, do not of course show that copper deficiency never occurs in babies suffering from iron deficiency. It is possible, for example, that a baby might be born with insufficient copper as the result of a maternal dietetic deficiency, and so develop a nutritional anæmia due to both copper and iron deficiency. However, iron salts with only minute and presumably insignificant traces of copper have been found effectual in the treatment of this anæmia in many countries of the world, and the line of argument used in this paper would indicate that, in other regions as in London, copper deficiency in babies is uncommon.

When considering possible copper deficiency the varying copper content of milk is of considerable interest. Human milk being richer in copper than cows' milk, it can be assumed that copper deficiency is more likely to occur in bottle-fed babies. Another point of importance is the copper content of ordinary fluid cow's milk on the market as compared with the copper content of milk obtained under special precautions to prevent any copper contamination. It appears that copper contamination is extremely common in milk and will materially increase its percentage of copper. Thus if milk is pasteurized in contact with copper the following comparative values have been obtained :-

Quam \& Hellwig: before pasteurization: 0.26-0.52 mgrm. Cu per litre; after pasteurization: 0.60-0.70 mgrm. $\mathrm{Cu}$ per litre; and

Görter, et al. $^{3}$ : before pasteurization: 0.09-0.14 mgrm. Cu per litre; after pasteurization: 0.17-0.29 mgrm. $\mathrm{Cu}$ per litre.

In the dried milk used for the control cases in our work on infantile anæmia $^{8}$ estimations of copper in two samples gave $0.19 \mathrm{mgrm}$. Cu (Professor 
E. B. Hart), and 0.25 mgrm. Cu (Dr. F. Carr) per litre of reconstituted milk,

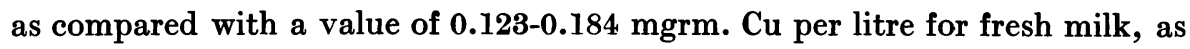
estimated by Elvehjem, Steenbock and Hart by the same technique. Hence it is possible that the copper contamination of cow's milk given to babies may actually be a factor of importance in preventing copper deficiency.

The fact that large doses of iron salts are desirable in the treatment of anæmia has by some been explained on the hypothesis that the traces of copper present in these salts are of fundamental importance, but if the conclusions here set out are correct, then as regards nutritional anæmia in babies, at any rate, this hypothesis falls to the ground.

\section{Summary.}

The part played by copper in the common nutritional anæmia of infancy is discussed, and the response in individual infants to treatment with iron and ammonium citrate plus copper sulphate, is compared with the response to iron and ammonium citrate alone.

The conclusion reached is that although copper deficiency may occur in isolated cases of nutritional anæmia it plays no part in the great majority of cases seen in London, and that this probably holds good for other parts of the world.

The author offers her thanks for their help and co-operation to the resident medical staff and nursing staff of the Queen's Hospital for Children, and especially to. Miss E. K. Wackett, the ward sister who had charge of the majority of the children treated with iron and copper.

\section{REFERENCES.}

1. Elvehjem, C. A., Steenbock, H., \& Hart, E. B., J. Biol. Chem., N.Y., 1929, LXXXIII, 21.

2. Elvehjem, C. A., \& Sherman, W. C., Ibid, 1932, XCVIII, 309.

3. Görter, E., Grendel, F., \& Weyers, W. A. M., Rév. franç. de péd., Paris, 1931, VII, 747.

4. Hart E. B., Steenbock, H., Waddel, J., \& Elvehjem, C. A., J. Biol. Chem., N.Y., 1928, LXXVII, 797.

5. Josephs, H. W., Bull. Johns Hopkins Hosp., Baltimore, 1931, XLIX, 246.

6. Josephs, H. W., J. Biol. Chem., N.Y., 1932, XCVI, 558.

7. Josephs, H. W., Bull. Johns Hopkins Hosp., 1932, LI, 185.

8. Mackay, H. M. M., \& Goodfellow, L., Med. Res. Council, London, 1931, Sp. Rep.

9. Loc. cit., 99.

10. Loc. cit., 28.

11. Loc. cit., 34.

12. Loc. cit., 77, 


\section{SYNOPSIS OF CASES SHOWN IN GRAPH I.}

\section{Cases treated with iron and ammonium citrate plus copper sulphate.}

H. F. Birth weight $7 \frac{1}{2}$ lb. Age 13 months; well nourished; weight 19 lb.; evidence of healed rickets. Given a mixed diet. Anæmia treated with iron and amonium citrate and copper sulphate. Hæmoglobin rose from 57 to $68 \%$, i.e., $11 \%$, in 16 days. Child treated as in-patient. Gained $2 \mathrm{lb} .2 \mathrm{oz}$. in 17 days. Discharged on account of infection in ward.

C. H. Twin, birth weight $4 \mathrm{lb}$. Age 13 months; very undersized; weight 12 lb. $9 \frac{3}{4}$ oz. Suffering from rickets and anæmia, and a persistent nasal discharge. Fed on milk and cereal only until admission. Put gradually on to a mixed diet and cod liver oil. Anæmia treated with iron and ammonium citrate and copper sulphate. Hæmoglobin rose from 38 to $78 \%$, i.e., $40 \%$, in 56 days. Child treated as in-patient. Weight remained almost stationary during this period.

C. S. Birth weight unknown, said to be premature. Age 10 months; undersized, rather thin; weight $11 \mathrm{lb}$. $10 \frac{3}{4} \mathrm{oz}$. Bottle fed till admission. Put gradually on to a mixed diet. Anæmia treated with iron and ammonium citrate and copper sulphate. Hæmoglobin rose from 42 to $62 \%$, i.e., a rise of $20 \%$, in 28 days. Child treated as in-patient. Gained $11 \mathrm{oz}$. in one month.

\section{Cases treated with iron and ammonium citrate alone.}

W. H. Twin, small at birth. Age 16 months, weight 14 lb. 14 oz. Given a mixed diet. Anæmia treated with iron and ammonium citrate alone. Hæmoglobin rose from 31 to $66 \%$, i.e., $35 \%$, in 24 days. Child treated as in-patient.

K. R. Birth weight $6 \mathrm{lb} .15 \mathrm{oz}$. Age 2 years and 9 months; well nourished but small for age; weight $25 \mathrm{lb}$. $6 \mathrm{oz}$; suffering from rickets. Given a mixed diet and cod liver oil. Anæmia treated with iron and ammonium citrate alone. Hæmoglobin rose from 45 to $76 \%$, i.e., $31 \%$, in 49 days. Child treated as in-patient at first, subsequently as out-patient, and gained $2 \mathrm{lb}$. $6 \frac{1}{2}$ oz. in 50 days.

\section{Case treated with saccharated ferrous carbonate.}

A. W. Birth weight unknown. Aged 15 months. Well nourished; weight 20 lb. 14 oz.; mentally backward. Given a diet consisting chiefly of milk and cereal with some fruit and vegetable daily. Anæmia treated with saccharated ferrous carbonate. Hæmoglobin rose from 39 to $77 \%$, i.e., a rise of $38 \%$, in 53 days, in spite of an attack of double otorrhœa. Child treated as in-patient, gained $2 \mathrm{lb} .1 \mathrm{oz}$. in 53 days.

\section{SYNOPSIS OF CASES SHOWN IN CHART II.}

\section{Cases treated with iron and ammonium citrate plus copper sulphate.}

T. A. Birth weight $6 \mathrm{lb}$. Age 11 months. Fairly well nourished, very flabby; weight $18 \mathrm{lb}$. $1 \mathrm{oz}$. Given mixed diet. Anæmia treated with iron and ammonium citrate and copper sulphate, the copper sulphate was begun two weeks before the iron. Hæmoglobin rose from 63 to $76 \%$, i.e., $13 \%$, in 42 days after iron started. Child treated as out-patient. Gained $12 \mathrm{oz}$. in this period.

K. P. Birth weight $8 \mathrm{lb}$. Age 20 months. Very small and thin; weight 13 lb. 8 oz.; suffering from severe active rickets. Diet up to time of admission was dried milk and orange juice. Put gradually on to a mixed diet, and given calciferol, 
Anæmia treated with iron and ammonium citrate and copper sulphate. Hæmoglobin rose from 58 to $\mathbf{8 0} \%$, i.e., $\mathbf{2 2} \%$, in $\mathbf{5 6}$ days. Child treated as in-patient. Gained 2 lb. 14 oz.

R. C. Birth weight $6 \mathrm{lb}$. $4 \mathrm{oz}$. Age 11 months. Nutrition poor; weight $15 \mathrm{lb} .4 \mathrm{oz}$; history of a recent attack of enteritis. Fed on dried milk till admission. Put gradually on to a mixed diet. Anæmia treated with iron and ammonium citrate and copper sulphate (very small dose of copper, see text). Hæmoglobin rose from 34 to $50 \%$, i.e., $16 \%$, in 59 days. Child treated as in-patient, and gained only $6 \mathrm{oz}$. in that time, though there was no evidence of any infection until he developed measles at the end of the period of observation.

\section{Case treated with iron and ammonium citrate alone.}

D. N. Twin, birth weight $3 \frac{1}{2}$ lb. Age $7 \frac{1}{2}$ months. Well nourished, weight $15 \mathrm{lb} .2$ oz. Fed on dried milk till admission and was changed gradually on to a mixed diet. Anæmia treated with iron and ammonium citrate. Hæmoglobin rose from 46 to $76 \%$, a rise of $30 \%$, in 91 days. Treated first as an in-patient, later as an out-patient; gained $5 \mathrm{lb} .1 \frac{1}{2} \mathrm{oz}$. in this period.

\section{Case treated with saccharated ferrous carbonate.}

J. C. Birth weight unknown: said to be premature. Age 16 months. Well nourished; weight $20 \mathrm{lb}$. $0 \frac{1}{2} \mathrm{oz}$; ; suffering from rickets. Given diet consisting chiefly of milk and cereals with some fruit and vegetables daily and cod liver oil. Anæmia treated with saccharated ferrous carbonate. Hæmoglobin almost stationary for first 6 weeks at about $55 \%$, thereafter rose to $71 \%$, i.e., by $16 \%$, in another 21 days, without change in treatment, making a total rise of $16 \%$ in 63 days. Child treated as an in-patient, gained $1 \mathrm{lb} .11 \frac{1}{2} \mathrm{oz}$. in 63 days. 